\title{
A Model of Insulin Resistance in Mice, Born to Diabetic Pregnancy, Is Associated with Alterations of Transcription-Related Genes in Pancreas and Epididymal Adipose Tissue
}

\author{
Akadiri Yessoufou, ${ }^{1,2,3}$ Kabirou Moutairou, ${ }^{2}$ and Naim Akhtar Khan ${ }^{1}$ \\ ${ }^{1}$ Faculty of Life Sciences, University of Bourgogne, UPRES EA 4183 Lipides et Signalisation Cellulaire, \\ 6 Boulevard Gabriel, 21000 Dijon, France \\ ${ }^{2}$ Laboratory of Cell Biology and Physiology, Department of Biochemistry and Cellular Biology, Faculty of Sciences and Techniques, \\ University of Abomey-Calavi and Institute of Biomedical and Applied Sciences (ISBA), 01 BP 918 Cotonou, Benin \\ ${ }^{3}$ Centre for Integrative Genomics, University of Lausanne, Bâtiment Génopode, 5è Etage, 1015 Lausanne, Switzerland
}

Correspondence should be addressed to Akadiri Yessoufou, akadiri.yessoufou@unil.ch

Received 7 June 2010; Accepted 30 August 2010

Academic Editor: Francesco Saverio Papadia

Copyright (C) 2011 Akadiri Yessoufou et al. This is an open access article distributed under the Creative Commons Attribution License, which permits unrestricted use, distribution, and reproduction in any medium, provided the original work is properly cited.

\begin{abstract}
Objective. This study is conducted on a model of insulin-resistant (IR) mice born to dams which were rendered diabetic by the administration of streptozotocin. Methods. Adult IR and control offspring were selected and we determined the mRNA expression of transcription factors known to modulate pancreatic and adipose tissue activities and inflammation. Results. We observed that serum insulin increased, and the mRNA of insulin gene transcription factors, Pdx-1, Nkx6.1 and Maf-A, were upregulated in IR mice pancreas. Besides, their pancreatic functional capacity seemed to be exhausted as evidenced by low expression of pancreatic Glut2 and glucokinase mRNA. Though IR offspring exhibited reduced epididymal adipose tissue, their adipocytes seemed to be differentiated into macrophage-like cells, as they exhibited upregulated CD14 and CD68 antigens, generally expressed by macrophages. However, there was no peripheral macrophages infiltration into epididymal adipose tissue, as the expression of F4/80, a true macrophage marker, was undetectable. Furthermore, the expression of IL- 6 , TNF- $\alpha$ and TLR-2, key players of insulin resistance, was upregulated in the adipose tissue of IR offspring. Conclusion. Insulin resistant state in mice, born to diabetic pregnancy, alters the expression of function-related genes in pancreas and epididymal adipose tissue and these offspring are prone to develop metabolic syndrome.
\end{abstract}

\section{Introduction}

Hyperglycemia, related to insulin resistance, is due to a decrease in peripheral glucose uptake, and to an increase in hepatic glucose production [1]. In order to induce insulin resistance, most of the investigators have adopted a strategy in which they feed the rodents with high-fat diets $[2,3]$. However, this dietary intervention is not well standardized, and the high-fat-induced phenotype varies distinctly among different studies [3]. It is obvious that appropriate animal models are crucial to study the pathogenesis and therapy of this complex metabolic disorder. From a scientific and an ethical point of view, it is reasonable to obtain a disease model which should resemble to the pathogenesis in human beings.

In our laboratory, we have developed a model of insulin resistance in macrosomic rats born to streptozotocin- (STZ-) induced diabetic dams $[4,5]$. These macrosomic offspring of diabetic dams were hyperglycemic, hyperinsulinemic, and they exhibited high serum and liver lipid levels during adulthood. Recently, we have also developed a model of insulin resistance in mice born to the STZ-induced diabetic animals [6]. The pups and their diabetic mothers were fed the standard laboratory chow. These offspring developed 
a marked hyperinsulinemia, hyperglycemia, and insulin resistance at adulthood [6]. In the present report, we assessed the pancreatic $\beta$-cell functions by determining the mRNA levels of Glut2 and glucokinase. We also examined the expression of some major insulin gene transcription factors like pancreatic and duodenal homeobox- (Pdx-) 1, NK6 transcription factor related-locus-1 (Nkx6.1), and Maf-A $[7,8]$. Nkx6.1 is important for the terminal differentiation of $\beta$-cells [8] and is known to influence glucose-induced insulin secretion [9]. Pdx-1 regulates the transcription of insulin, glucokinase, and islet amyloid polypeptide [7, 8]. Moreover, Pdx-1 and Maf-A can exert their positive actions separately on the promoter and their effects are additive [10]. Therefore, we determined the expression of pancreatic mRNA of these transcription factors in order to respond to the question whether they are involved in the $\beta$-cell adaptation in response to insulin resistance.

Because adipokines, secreted by adipose tissue, play crucial role in the onset of type II diabetes and obesity [11], we determined the mRNA encoding for leptin and adiponectin in epididymal adipose tissue. Moreover, macrophages have been shown to infiltrate several organs, including adipose tissue, during inflammatory processes [12]. We, therefore, investigated the expression of mRNA of CD14, CD68, and F4/80 antigens in the epididymal adipose tissue of these animals. CD14 has been shown to bind to lipopolysaccharide (LPS) which interacts with Toll-like receptors (TLR) [13], and this spurred us to examine the expression of TLR-2 mRNA in epididymal adipose tissue. The mRNA expression of tumour necrosis factor- (TNF-) $\alpha$ and interleukin- (IL-) 6 was determined as these agents are also known to be secreted in adipose tissue [14]. In order to shed light whether $\mathrm{T}$ cells infiltrate the adipose tissue of insulin-resistant (IR) mice, we also investigated the mRNA expression of T cell receptor-alpha (TCR $\alpha$ ), regulated on activation of normal $\mathrm{T}$ cell expressed and secreted (RANTES) and its receptor CCR-5 in the epididymal adipose tissue.

All the aforementioned parameters were studied in adult control and IR mice which were, respectively, the descendents of control and diabetic dams, since the rationale of the present study is to explore the metabolic consequences of a pathologic model of insulin resistance of in utero exposure to hyperglycemia, that is, diabetic pregnancy.

\section{Materials and Methods}

2.1. Animals and Design. The study was performed on wild type C57BL/6J mice (Charles River, Les Oncins, France) at age of 3 months. The insulin-resistant (IR) offspring of diabetic mice were obtained as described elsewhere [6]. Briefly, after mating, the first day of gestation was determined by the presence of spermatozoids in vaginal smears. Pregnant mice ( $n=8$, at age of 3 months), housed individually in wood-chip-bedded plastic cages at constant temperature $\left(25^{\circ} \mathrm{C}\right)$ and humidity $(60 \pm 5 \%)$ with a 12 hours light-dark cycle, were rendered diabetic by five daily intraperitoneal injections of streptozotocin $(40 \mathrm{mg} / \mathrm{kg}$ body weight in $0.1 \mathrm{M}$ citrate buffer, $\mathrm{pH} 4.5$ ), starting on day 5 of gestation [15]. Another group of pregnant mice $(n=8)$ were also injected with the vehicle alone and considered as control groups. The glycemia was followed during gestation of mice as we described previously [6]. All diabetic dams included, in this study, had the fasting blood glucose levels above $1.23 \mathrm{~g} / \mathrm{L}$. The success rate in obtaining the diabetic dams was $87.5 \%$. In the litters of diabetic dams, the mean proportion of hyperglycemic pups at birth was $94.6 \pm$ $3 \%$. Only 12 male offspring born to diabetic dams, which were hyperglycemic at birth and showed a hyperglycemia and a hyperinsulinemia at 3 months of age, were selected and included in the study, since reproductive hormones have been associated with prevalence, susceptibility, and severity of obesity and autoimmune disease $[16,17]$. The nonhyperglycemic pups of diabetic mothers were excluded, as maternal diabetes related to fetal hyperglycemia was the criterion for the selection of our experimental population [5]. However, these nonhyperglycemic offspring of diabetic mothers were not hyperinsulinemic, neither at birth nor at adulthood. They had normal growth and did not show any significant difference from the control pups in serum lipids.

The dams and offspring (after weaning) were fed the standard laboratory chow. The principles of laboratory animal care (NIH publication No. 86-23, revised 1985) were followed, as well as specific national laws (e.g., the current version of the German Law on the Protection of Animals) where applicable. The experimental protocol was also approved by the Regional Ethical Committee.

2.2. Oral Glucose-Tolerance and Insulin-Tolerance Tests. Oral glucose-tolerance test (OGTT) was carried out in 12 hyperglycemic offspring and 12 control offspring after a 15-h fast. Briefly, a single dose of glucose was orally administrated ( $3 \mathrm{~g} / \mathrm{kg}$ body weight) to the mice. Glycemia was measured using One Touch ULTRA Glucometer (LifeScan, Johnson and Johnson, USA), every 5 or 10 minutes for 2 hours following glucose loading, by cutting off the tip of tail and squeezing it gently.

For intraperitoneal insulin-tolerance test (IPITT), a single dose of insulin ( $0.5 \mathrm{U} / \mathrm{kg}$ body weight; Actrapid Novo, Copenhagen, Denmark) was injected intraperitoneally after 4-h fast and, as in the oral glucose-tolerance tests, glycemia was measured every 5 or 10 minutes for 2 hours, following insulin injection.

2.3. Blood, Liver, Pancreas, and Epididymal Adipose Tissue Samples. After overnight fasting, animals (3 monthsages) were anesthetized with pentobarbital $(60 \mathrm{mg} / \mathrm{kg}$ body weight). Blood was drawn from the abdominal aorta. Serum was obtained by low-speed centrifugation $(1000 \mathrm{~g} \times 20 \mathrm{~min}$ utes) and used for glucose (glucose oxydase method, Beckman Instruments, USA) and insulin determination (ELISA kit, LINCO Research Inc, St. Charles, MO, USA). Pancreas, epididymal adipose tissue, and livers, after removal, were weighed then frozen in liquid nitrogen and used for total RNA extraction. 
2.4. Determination of Serum and Liver Lipids. After total lipid extraction, according to the method of Bligh and Dyer [18] serum or liver triglyceride (TG) and free fatty acids (FFA) were separated on silica gel by thin layer chromatography (TLC) and the purified fractions of FFA and TG were quantified by gas liquid chromatography $[6,19]$.

2.5. Real-Time RT-PCR Quantification Assay. Total RNA was prepared using Trizol reagent (Invitrogen Life Technologies, Groningen, The Netherlands) according to the manufacturer's instructions. The integrity of RNA was electrophoretically checked by ethidium bromide staining and by the OD absorption ratio OD260 nm/OD280 nm more than 1.9. One microgram of total RNA was reverse transcribed with Superscript II RNAse H-reverse transcriptase using oligo (dT) according to the manufacturer's instructions (Invitrogen Life Technologies, France). Real-time PCR was performed on an iCycler iQ real-time detection system (Bio-Rad, Hercules, CA, USA) as described elsewhere [6]. Briefly, the amplification was done by using SYBR Green I detection (SYBR Green JumpStart, Taq ReadyMix for Quantitative PCR, Sigma). Oligonucleotide primers, used for mRNA analysis, were based on the sequences of mice gene in GenBank database. The sequence of the reference gene used for normalization of RT-PCR gene expression data is the $\beta$-actin (forward: $5^{\prime}$-AGAGGGAAATCGTGCGTGAC$3^{\prime}$; reverse: $5^{\prime}$-CAATAGTGATGACCTGGCCGT-3'). All mice RT-PCR primer sets used to amplify the genes in these studies are presented in Table 1. All determinations were performed, in duplicates using two dilutions of each assay to achieve reproducibility. Results were evaluated by iCycler iQ software including standard curves, amplification efficiency $(E)$, and threshold cycle (Ct). Relative quantitation of mRNA expression of a large number of signalling factors in different groups was determined using the $\Delta \Delta \mathrm{Ct}$ method, in which $\Delta \Delta \mathrm{Ct}=\Delta \mathrm{Ct}$ of gene of interest $-\Delta \mathrm{Ct}$ of $\boldsymbol{\beta}$ actin. $\Delta \mathrm{Ct}=\mathrm{Ct}$ of interest group - $\mathrm{Ct}$ of control group. Relative quantity (RQ) was calculated as follows: $\mathrm{RQ}=(1+E)^{(-\Delta \Delta \mathrm{Ct})}$.

2.6. Statistical Analysis. Results are shown as means \pm SEM. Statistical analysis of data was carried out using STATISTICA (version 4.1, Statsoft, Paris, France). Data were evaluated by analysis of variance. Duncan's Multiple-Range test and the Student's $t$-test were employed for the comparison between diabetic and control dams, and the IR offspring with their corresponding controls, respectively. Differences were considered significant at $P<.05$.

\section{Results}

3.1. Glycemia during Oral Glucose- and Insulin-Tolerance Tests. During OGTT, the glycemia was higher in the offspring of diabetic dams as compared with their corresponding controls (Figure 1(a)). The area under glucose curve during the time of the test was $304.95 \mathrm{~g} / \mathrm{L} * 120$ minutes for offspring of diabetic dams, as compared to that of control offspring which was $175.80 \mathrm{~g} / \mathrm{L} * 120$ minutes. Two hours after glucose loading, glycemia was not back to its basal value
TABLE 1: Gene regions amplified and their corresponding primer sequences used for RT-PCR.

\begin{tabular}{|c|c|}
\hline Genes amplified & Primer sequences \\
\hline \multirow[t]{2}{*}{ Mouse RANTES } & F: 5'-GCAGTCGTGTTTGTCACTCG-3' \\
\hline & R: 5' -TAGGACTAGAGCAAGCGATGAC-3' \\
\hline \multirow[t]{2}{*}{ Mouse CCR5 } & F: 5'-GCCTAAACCCTGTCATCTATGC-3' \\
\hline & R: 5'-ATATTTCCCGGCCCTGATAAAAG-3' \\
\hline \multirow[t]{2}{*}{ Mouse MCP-1 } & F: 5'-GAGAGCCAGACGGGAGGAAG-3' \\
\hline & R: 5' -TGAATGAGTAGCAGCAGGTGAG-3' \\
\hline \multirow[t]{2}{*}{ Mouse CD68 } & F: 5'-TTCAGGGTGGAAGAAAGGTAAAGC-3' \\
\hline & R: 5' -CAATGATGAGAGGCAGCAAGAGG-3' \\
\hline \multirow[t]{2}{*}{ Mouse IL-6 } & F: 5'-CCGCTATGAAGTTCCTCTCTGC-3' \\
\hline & R: 5'-ATCCTCTGTGAAGTCTCCTCTCC-3' \\
\hline \multirow[t]{2}{*}{ Mouse TCR $\alpha$} & F: 5' -CCTCTACAGCAGCGTTCTCATCC-3' \\
\hline & R: 5'-GGGTAGGTGGCGTTGGTCTCTTTG-3' \\
\hline \multirow[t]{2}{*}{ Mouse CD14 } & F: 5'-GCGTGTGCTTGGCTTGTTG-3' \\
\hline & R: 5'-CAGGGCTCCGAATAGAATCCG-3' \\
\hline \multirow[t]{2}{*}{ Mouse F4/80 } & F: $5^{\prime}$-TCCAGCACATCCAGCCAAAGC- $3^{\prime}$ \\
\hline & R: 5' -CCTCCACTAGCATCCAGAAGAAGC-3' \\
\hline \multirow[t]{2}{*}{ Mouse TLR-2 } & F: 5'-CTACAGTGAGCAGGATTCC-3' \\
\hline & R: 5'-CAGCAAAACAAGGATGGC-3' \\
\hline \multirow[t]{2}{*}{ Mouse TNF- $\alpha$} & F: 5' -CTCTTCTCATTCCTGCTTGTGG-3' \\
\hline & R: 5'-AATCGGCTGACGGTGTGG-3' \\
\hline \multirow[t]{2}{*}{ Mouse SREBP-1c } & F: 5'-CATCAACAACCAAGACAGTC-3' \\
\hline & R: 5'-CCAGAGAAGCAGAAGAGAAG-3' \\
\hline \multirow[t]{2}{*}{ Mouse FAT/CD36 } & F: 5' -TGCTCTCCCTTGATTCTGCTGC-3' \\
\hline & R: 5' -TTTGCTGCTGTTCTTTGCCACG-3' \\
\hline \multirow[t]{2}{*}{ Mouse Adiponectin } & iF: 5'-GCCGCTTATGTGTATCGCTCAG-3' \\
\hline & R: 5'-GCCAGTGCTGCCGTCATAATG-3' \\
\hline \multirow[t]{2}{*}{ Mouse Leptin } & F: 5'-ACACACGCAGTCGGTATCC-3' \\
\hline & R: 5'-GAGTAGAGTGAGGCTTCCAGG-3' \\
\hline \multicolumn{2}{|c|}{ Mouse GlucokinaseF: 5' -AGAAGGCTCAGAAGTTGGAGAC-3' } \\
\hline & R: 5'-GGATGGAATACATCTGGTGTTTCG-3' \\
\hline \multirow[t]{2}{*}{ Mouse Insulin } & F: 5- TGGCTTCTTCTACACACCCAT-3' \\
\hline & R: 5'-CTCCAGTGCCAAGGTCTGAA-3' \\
\hline \multirow[t]{2}{*}{ Mouse Glut2 } & F: 5'-TGTGGTGTCGCTGTTTGTTG-3' \\
\hline & R: 5'-AATGAAGTTTGAGGTCCAGTTGG-3' \\
\hline \multirow[t]{2}{*}{ Mouse C/EPB- $\beta$} & F: 5'-AGCTGAGCGACGAGTACAAG-3' \\
\hline & R: 5'-AGCTGCTCCACCTTCTTCTG-3' \\
\hline \multirow[t]{2}{*}{ Mouse Maf-A } & F: 5'-ATCACTCTGCCCACCATCAC-3' \\
\hline & R: 5'-CGCCAACTTCTCGTATTTCTCC-3' \\
\hline \multirow[t]{2}{*}{ Mouse Nkx6-1 } & F: 5'-GGGTCTTCCTCCTCCTCCTC-3' \\
\hline & R: 5'-GGTCTGGTGTGTTTTCTCTTCC-3' \\
\hline \multirow[t]{2}{*}{ Mouse Pdx-1 } & F: 5'-CTACTGCCTTCGGGCCTTAG-3' \\
\hline & R: 5' -TTGGAACGCTCAAGTTTGTACC-3' \\
\hline
\end{tabular}

in hyperglycemic offspring. In response to insulin injection, the decrease in glycemia was less marked in hyperglycemic offspring, suggesting decreased insulin sensitivity, that is, an insulin resistance in these mice (Figure 1(b)). Though, in IR offspring (hyperglycaemic), glycemia was back to its basal value, 120 minutes after insulin injection, it remained lower in controls. 


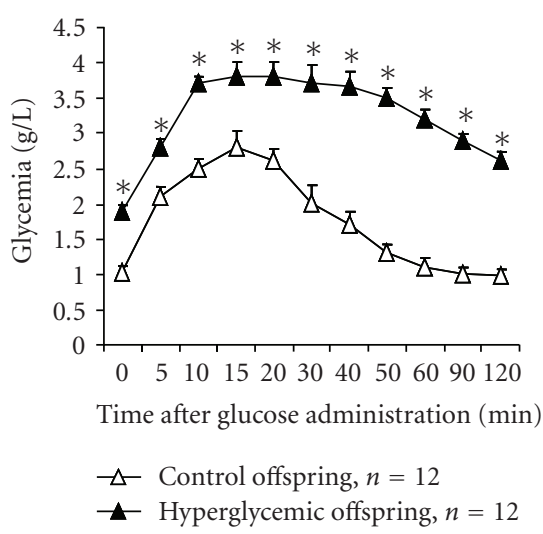

(a)

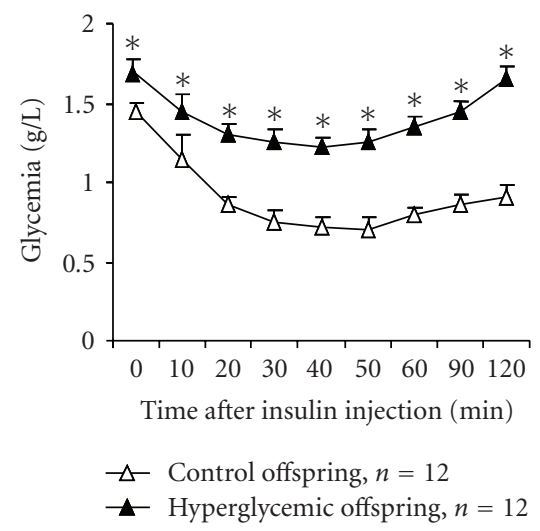

(b)

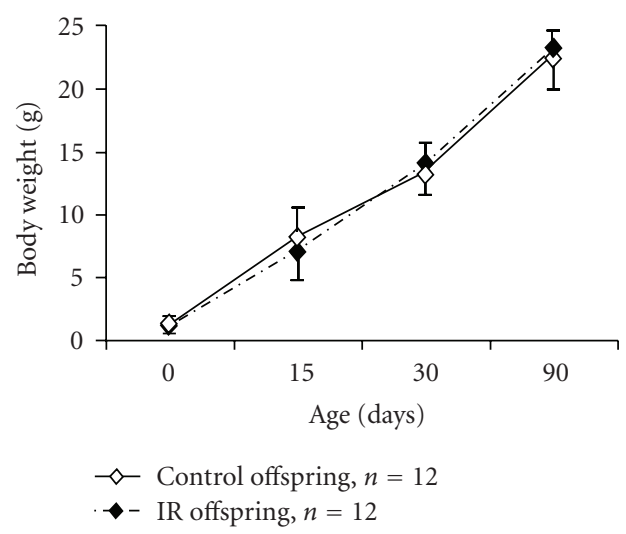

(c)

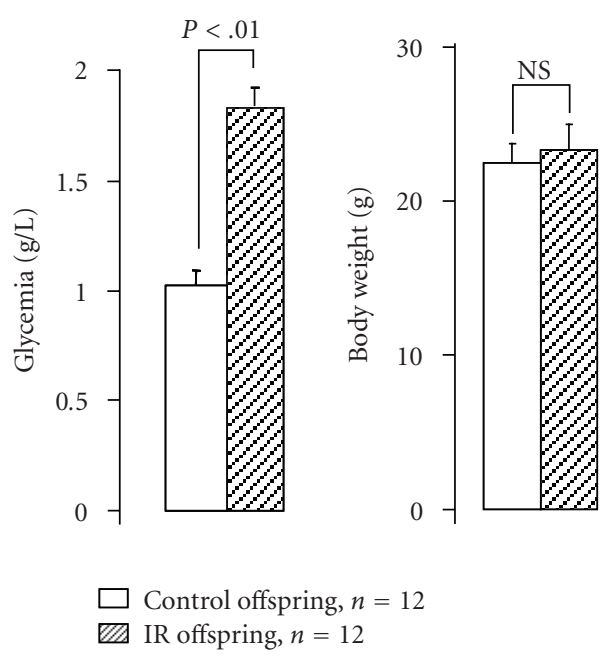

(d)

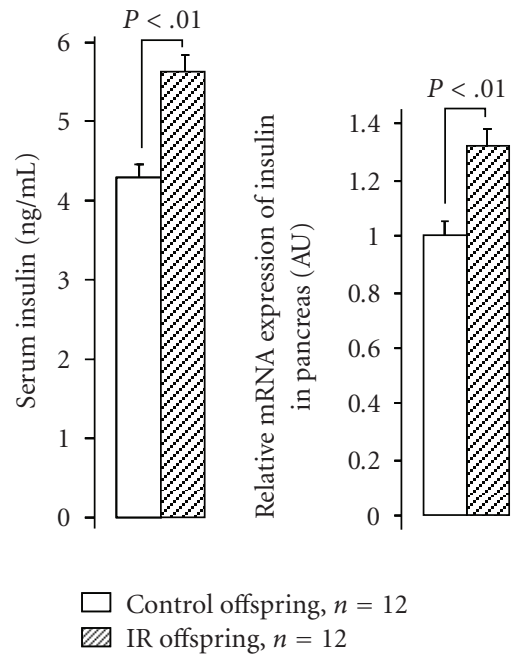

(e)

Figure 1: (a) Oral glucose-tolerance tests (OGTT). Glycemia during OGTT (3 g/kg-body weight) was measured after a 15-h fast, every 5-10 minutes, for 120 minutes following glucose administration. (b) Intraperitoneal insulin-tolerance tests (IPITT). Glycemia during IPITT ( $0.5 \mathrm{U} / \mathrm{kg}$ body weight) was measured after a 4 -h fast, every $5-10$ minutes, for 120 minutes following insulin injection. $* P<.01$ significant difference between control offspring (open triangle) and hyperglycemic offspring (solid triangle). (c) Evolution of the body weight of the offspring from birth until 3 months of age. Open Square corresponds to control offspring and Solid Square to IR offspring. (d) Glycemia and body weight at 3 months. (e) Serum insulin and insulin mRNA expression in the pancreas. Glycemia, serum insulin, and its mRNA expression were determined as described in Section 2. The offspring were weighed during the study until the age of 3 months. The dams and the offspring after weaning were fed the standard laboratory chow. Values are means \pm SEM, $n=12$ per group of animals. AU: arbitrary units.

3.2. Glycemia, Body Weight, and Serum Insulin Concentration and Its mRNA Expression in Pancreas. There was no significant difference in the body weight between control and IR offspring, from their birth until 3 months of age (Figure 1(c)). However, the IR offspring were hyperglycemic and hyperinsulinemic and expressed high level of insulin transcript compared with their controls (Figures $1(\mathrm{~d})$ and $1(\mathrm{e}))$.

3.3. Maf-A, Nkx6-1, Pdx-1, C/EBP- $\beta$, Glut 2, and Glucokinase $m R N A$ Expression in the Pancreas. It is well known that glucose stimulates insulin release [9]. Moreover, Glut2 and glucokinase (GK) are implicated in the regulation of glucose metabolism gene transcription in $\beta$-cells $[20,21]$.
Besides, some factors like Pdx-1, Nkx6.1, and Maf-A are required for insulin gene transcription $[7,8]$. Assessment of the beta-cell functionality may need hyperglycemic clamp study and glucose-tolerance test. As we have performed the glucose-tolerance test and assessed some major insulin gene transcription factors, we therefore examined the relative quantitative expression of mRNA encoding for these factors in the pancreas and assessed, in the $\beta$-cells, the levels of Glut2 and glucokinase mRNA. Indeed, while C/EBP- $\beta$ mRNA was undetectable, IR offspring expressed higher MafA, Nkx6-1, and Pdx-1 transcripts than their corresponding controls (Figure 2(a)). Glut2 and GK mRNA expressions were downregulated in IR offspring compared to controls (Figure 2(b)). 


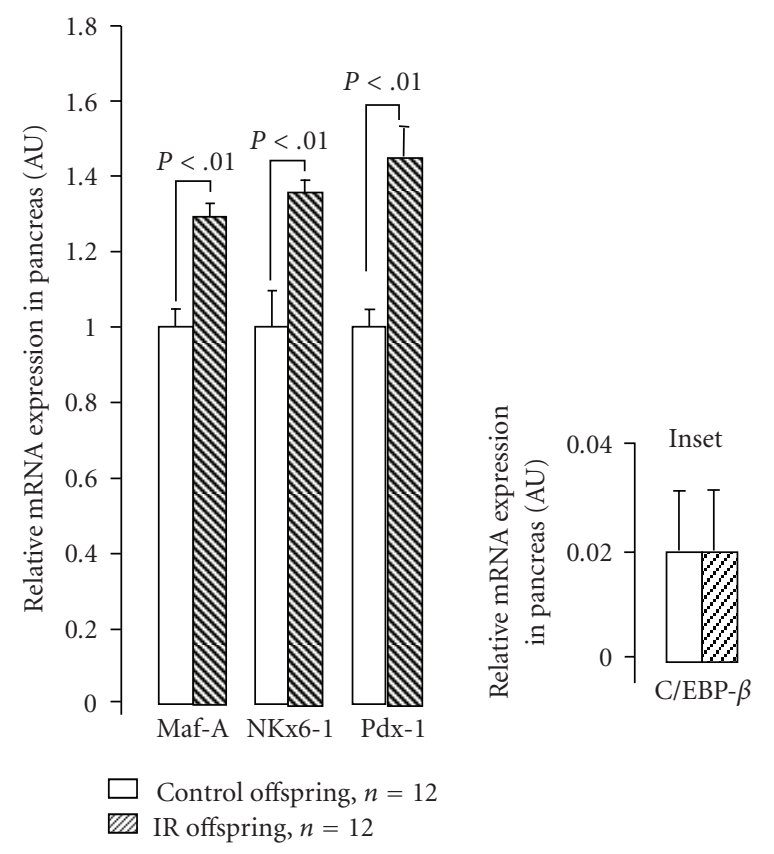

(a)

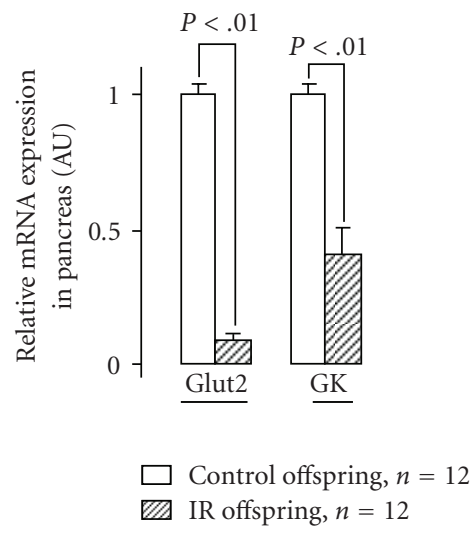

(b)

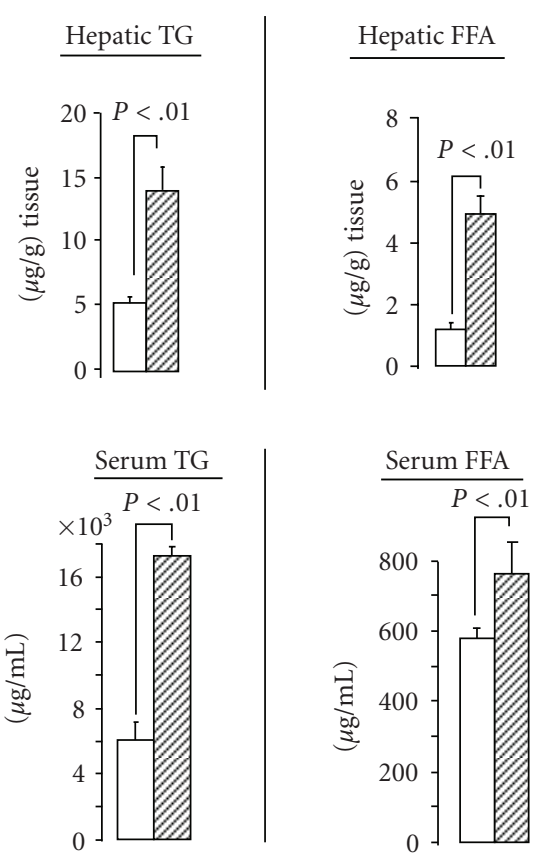

$\square$ Control offspring, $n=12$ UT IR offspring, $n=12$

(c)

Figure 2: Maf-A, Nkx6-1,Pdx-1, and C/EBP- $\beta$ (a), Glut2 and GK (b) mRNA expression in the pancreas of IR and control offspring. The expression of mRNA was quantitatively analyzed by employing real-time RT-PCR as described in Section 2. AU: arbitrary units. (c) Serum and hepatic triglyceride (TG) and free fatty acids (FFA) in IR and control offspring. The lipids were determined in serum and liver as described in Section 2. Values are means $\pm \mathrm{SEM}, n=12$ per group of animals. 
3.4. Serum and Hepatic TG and FFA Concentrations. Insulin resistance has been associated with hyperlipidemia [22]. Indeed, in the present study, IR offspring highly accumulated of TG and FFA in their liver and serum as compared to control animals (Figure 2(c)).

3.5. Adiposity, Adiponectin, Leptin, TNF- $\alpha$, and IL-6 mRNA Expression in Epididymal Adipose Tissue. Obesity has been linked to high adiposity and hyperlipidemia $[6,23]$. Moreover, it has been reported that chronic inflammation in fat plays crucial role in the development of insulin resistance [22]. Therefore, we assessed the weight of epididymal adipose tissue as well as the obesity-related parameters such as adiponectin and leptin and proinflammatory markers (TNF- $\alpha$ and IL-6). Indeed, IR offspring exhibited reduced epididymal adipose tissue mass than the control offspring (Figure 3(a)). The quantity of epididymal adipose tissue was positively correlated with the expression of mRNA of adiponectin ( $R^{2}=0.87$ in controls offspring versus $R^{2}=$ 0.90 in IR offspring) and leptin $\left(R^{2}=0.85\right.$ in controls offspring versus $R^{2}=0.95$ in IR offspring) (Figures 3(a) and $3(\mathrm{~b}))$. Conversely, IR offspring showed increased expression of proinflammatory markers which are IL- 6 and TNF- $\alpha$ in their epididymal adipose tissue (Figure 3(c)).

3.6. Liver Weight and FAT/CD36, SREBP-1c, TNF- $\alpha$ and IL-6, $m R N A$ Expression in the Liver. While the IR offspring exhibited reduced epididymal adipose tissue mass, they showed higher liver weight than that of the controls (Figure 3(d)). Consequently, the liver of IR offspring exhibited features of steatosis. Furthermore, FAT/CD36 is actively implicated in the uptake of lipids and, hence, may contribute to high lipid contents in the liver. Moreover, chronic inflammation has been reported as a link between insulin resistance and obesity, associated with lipid accumulation [22, 24]. We therefore examined the expression of lipid transporters and some proinflammatory markers in liver. Indeed, while the expression of FAT/CD36 mRNA was upregulated, that of SREBP-1c mRNA was downregulated in the liver of IR offspring compared to controls (Figure 3(e)). There was no significant difference in expression of IL-6 mRNA $(1.00 \pm 0.12$ versus $1.11 \pm 0.14)$ and TNF- $\alpha$ mRNA $(1.00 \pm 0.10$ versus $0.90 \pm 0.15)$ in the liver of both groups of mice.

3.7. CD14, CD68, F4/80, TCR $\alpha$, TLR-2, MCP-1, RANTES, and CCR5 mRNA Expression in Epididymal Adipose Tissue. Macrophages and $\mathrm{T}$ cells accumulation in adipose tissue characterized the inflammation in obesity $[12,14]$. Since inflammation has appeared as a link between insulin resistance and obesity and diabetes [24], we examined the level of macrophage and $\mathrm{T}$ cell markers in the epididymal adipose tissue of insulin-resistant offspring. While none of the mRNA expression of F4/80, MCP-1 (infiltrated macrophages' marker), TCR $\alpha$, RANTES, and CCR5 (infiltrated $\mathrm{T}$ cells' markers) was detectable from all animal groups, IR offspring expressed high level of CD14, CD68, and TLR-2 mRNA in their epididymal adipose tissue as compared to controls (Figures 4(a) and 4(b)).

\section{Discussion}

High-fat diet feeding induces obesity and metabolic disorders in rodents [3]. However, this dietary intervention is not well standardized. The question which type of high-fat diet is best to the model of human metabolic alterations remains unanswered. On the other hand, the use of monogenic models (such as the ob/ob mouse or the Zucker-(fa/fa) fatty rat) or pharmacologically-induced obesity models (such as the gold-thioglucose mouse) has raised some problems concerning the interpretation of the observed effects. The question of whether the results obtained arise from the obese phenotype or the model's genetic/pharmacological background is difficult to solve completely. These observations prompt researchers to generate obesity in animals by using fat-enriched (high-fat) diet strategies for several years now. Indeed, several studies have revealed that highfat diets promote hyperglycemia and whole body insulin resistance, and their effects on target organs have been examined. Based on this experience, it is generally accepted that high-fat diets can be used to generate a valid rodent model for the metabolic syndrome with insulin resistance and altered beta-cell function [25-27]. However, the real difficulty is the definition of the term "high-fat diet" itself and the standardization of the exact fat content and fat composition of the diets. Various high-fat diets have been used with relative fat fractions between $20 \%$ and $60 \%$ energy as fat, and the basic fat component varies between animal-derived fats [3]. Consequently, all these diets are summarized under the term high-fat diets in the literature. This has inevitably led to a considerable variability in the results reported. In the present study, we propose a new model of pathological insulin resistance associated with maternal diabetic pregnancy. Therefore, the present study is designed to shed light on the pathophysiological model of insulin resistance, related to diabetic pregnancy in mice. The insulin-resistant (IR) offspring, in our laboratory, have been obtained from pregnant animals which were rendered diabetic by the administration of streptozotocin [4-6]. As far as the model design is concerned, we would like to mention that maternal streptozotocin administration before pregnancy affects fertility and impairs embryo development during the preimplantation period [28]. However, like in the present study, the induction of diabetes by streptozotocin injection on day 5 of gestation has no effect on embryo development [29]. Moreover, we induced diabetes during the second half of the first trimester of pregnancy with five low doses of streptozotocin starting on day 5 of gestation to mimic type 1 diabetic pregnancy, following a T lymphocytedependent process $[30,31]$. Moreover, the administration of low doses of streptozotocin to rodents represents a good model of diabetes development, and this is for several reasons: (i) islet lesions in this experimental model resemble to those of human insulitis, with a predominance of $\mathrm{CD}^{+}$ $\mathrm{T}$ cells [30], (ii) the animals used are normal and do not have an underlying immune abnormalities like BB rat, being lymphopenic with few peripheral $\mathrm{CD}^{+} \mathrm{T}$ cells [32], and NOD mice which have systemic immune abnormalities [33], (iii) the onset of diabetes is controlled, and (iv) the Th1/Th2 


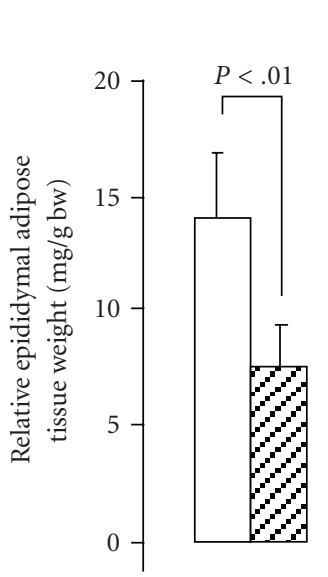

(a)

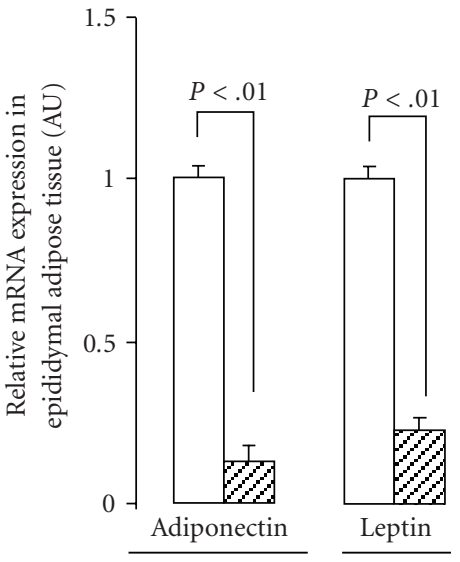

(b)

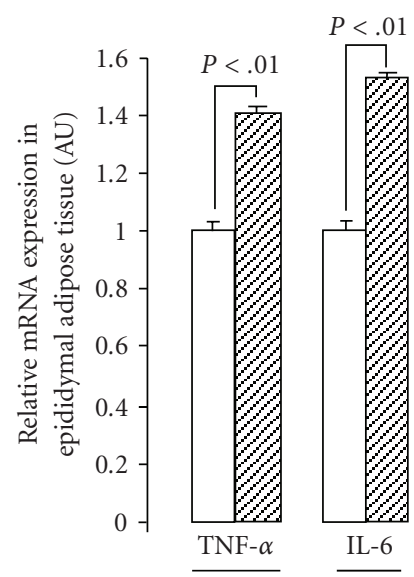

(c)

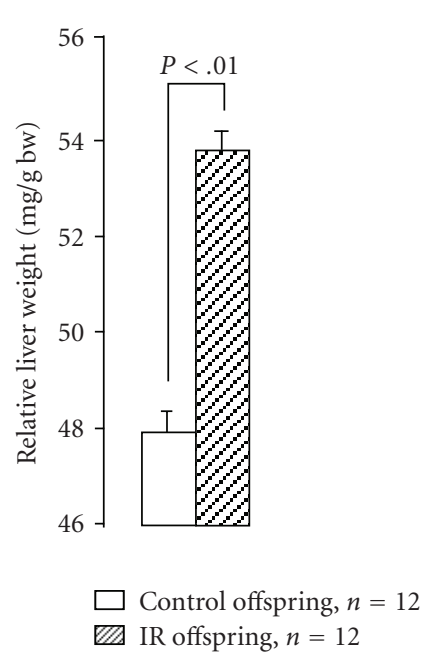

(d)

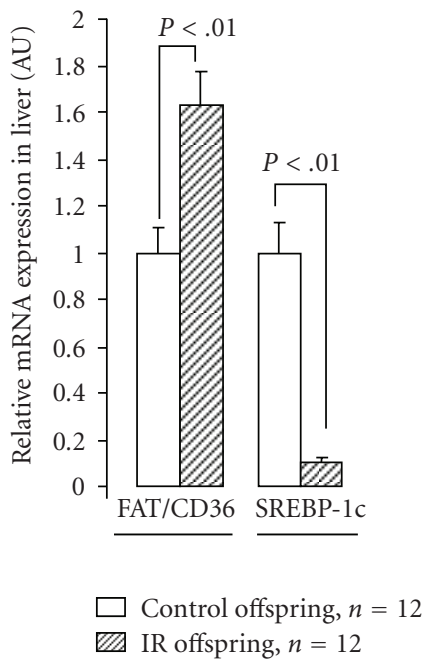

(e)

FIGURE 3: Relative epididymal adipose tissue weight (a) and adiponectin and leptin (b), and TNF- $\alpha$ and IL-6 (c) mRNA expression in epididymal adipose tissue. Relative liver weight (d) and FAT/CD36 and SREPB-1c mRNA expression in liver (e) of IR and control offspring. The liver and epididymal adipose tissue weights are expressed as milligrams $(\mathrm{mg})$ of the tissue per grams $(\mathrm{g})$ of body weight of mice. The expression of mRNA was quantitatively analyzed by employing real-time RT-PCR as described in Section 2 . Values are means \pm SEM, $n=12$ per group of animals. AU: arbitrary units. The quantity of epididymal adipose tissue was positively correlated with the mRNA expression of adiponectin and leptin two obesity-related parameters; $R^{2}=$ coefficient of correlation between the mass of epididymal adipose tissue and the level of the expression of adipokines (adiponectin and leptin) in each group of animals.

dichotomy can be observed during diabetes in these animals [30,34]. These IR offspring of diabetic dams showed, after OGTT, a high hyperglycemia compared with control offspring. Moreover, the IPITT demonstrated decreased insulin sensitivity in these mice. These observations confirmed a real insulin resistance in these offspring $[35,36]$.

The first and foremost question is how the hyperglycemia modulates pancreatic $\beta$-cell functions. We observed that IR mice born to diabetic dams had higher serum insulin levels and pancreatic insulin transcripts than control mice, in accordance with our previous observations $[5,6]$. Pancreatic $\beta$-cells produce and store insulin in response to physiological demand, and hyperglycemia, within 15 minutes, results in the activation of a complex network of intracellular signalling pathways that trigger insulin release [37]. The hyperinsulinemic state of IR offspring may be due to high expression of the major insulin gene transcription factors which are Pdx-1, Maf-A, and Nkx6 in their pancreas [38]. Indeed, other investigators have shown that the deletion of $\mathrm{Pdx}-1$ gene in the pancreas results in abnormally low insulin concentrations [39]. In our study, the glucose-induced hyperinsulinemia does not seem to be mediated by C/EBP$\beta$ as the expression of this repressor of insulin gene was not significantly altered in both groups of animals. Pancreatic $\beta$-cell function is associated to glucokinase activity [21]. IR mice exhibited low expression of glucokinase and Glut2 mRNA in the pancreas and this phenomenon might be responsible for impaired glucose transport and metabolism, thus contributing to high glucose concentration in these animals, as suggested by Ahlgren et al. [39] that reduced 


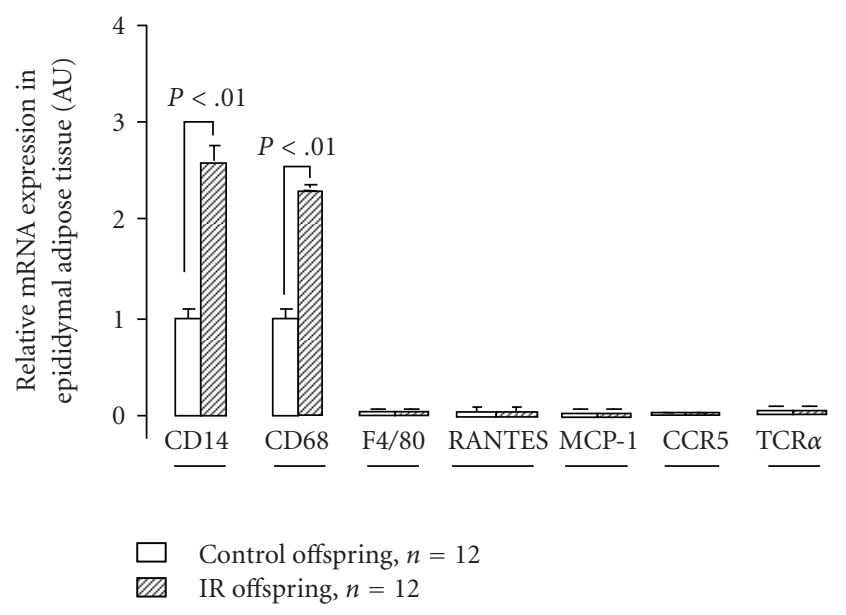

(a)

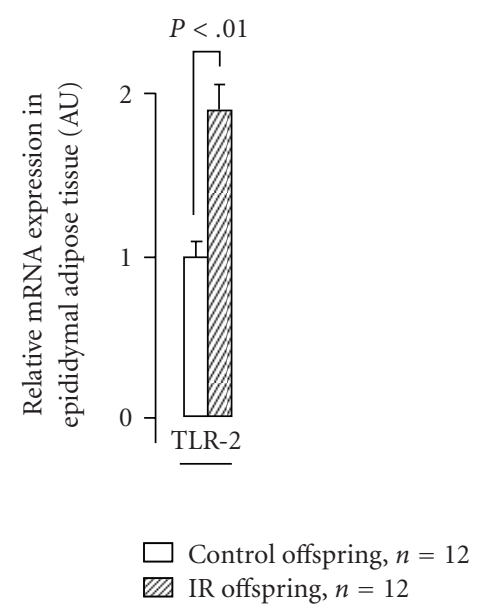

(b)

FIgURE 4: The mRNA expression of CD14, CD68, F4/80, RANTES, CCR5, MCP-1, TCR $\alpha$ (a), and TLR-2 (b) in epididymal adipose tissue of IR and control offspring. The expression of mRNA was quantitatively analyzed by employing real-time RT-PCR as described in Section 2 . Values are means \pm SEM, $n=12$ per group of animals. AU: arbitrary units.

Glut2 levels lead to hyperglycemia. Indeed, glucose has been shown to stimulate insulin release and the transcription of insulin gene and translation of the nascent mRNA in pancreatic $\beta$-cells [9]. Several investigators have interestingly demonstrated both in vivo and in primary culture in vitro, that the effect of glucose on glycolytic and lipogenic genes in GK knockout hepatocytes is lost because of the impaired ability of these cells to efficiently metabolize glucose [40]. Moreover, other investigators have shown that downregulation of SREBP-1c expression induces a markedly decrease in Glut2 expression [41]. Thus, we can state that the hyperglycemic state in IR offspring might be also due to the marked decreased expression of GK and Glut2, as these animals, in addition, exhibited low expression of SREBP1c which may contribute to decreased level of Glut2 [41]. However, it is useful to specify that this hyperglycemia in IR mice might also be due to low insulin sensitivity in target peripheral organs.

While the IR offspring exhibited reduced epididymal adipose tissue mass, they showed increased liver weight than the control offspring and, consequently, the liver of IR offspring showed features of steatosis. This could, at least in part, account for their similar body weight despite reduced epididymal adipose tissue mass in IR offspring which also abundantly accumulated FFA and TG $[5,6]$. It has been well established by several studies that diabetes mellitus induces hyperlipidemia in mothers and in their obese offspring [5, $42,43]$. In diabetic rats, high levels of triglyceride in maternal circulation may create a steep concentration gradient across the placenta, which accelerates their transport and deposition in fetal tissues [43]. This hypertriglyceridemia persists with age and has been linked to the development of insulin resistance and hyperlipogenesis [44]. Besides, IR offspring exhibited high levels of CD36/FAT which will again participate in high uptake of lipids by liver and will ultimately contribute to liver steatosis in these animals. Furthermore, the mRNA of SREBP-1c is downregulated in IR offspring. SREBP-1c controls the transcription of lipogenic genes. Hence, a high accumulation of TG and FFA in the liver, due to high expression of FAT/CD36, might be responsible for the low expression of SREBP-1c in these animals. On the other hand, some authors have demonstrated, in vivo and in vitro, that hepatic GK is required for synergistic action of SREBP$1 \mathrm{c}$ and ChREBP on glycolytic and lipogenic gene expression [40]. Other investigators have observed altered expression and activity of SREBP-1c in GK-knockout mice [45]. As the IR mice, in our study, expressed low GK, we can state that reduced expression of SREBP-1c might be due to the low expression of glucokinase mRNA.

Adipokines, secreted by adipose tissue, are required for a number of metabolic processes [46]. In this study, adiponectin and leptin levels were positively correlated with the epididymal adipose tissue mass which decreased in IR offspring. These observations are in accordance with our previous results in macrosomic infants of gestational diabetic women [47]. Furthermore, Guerre-Millo et al. [48] have also shown that high-fat diet-fed mice exhibited higher glucose levels and lower adiponectin concentrations than the standard diet animals. Hence, reduced adiponectin will again contribute to insulin resistance as this adipokine, an anti-inflammatory agent, has been shown to enhance insulin sensitivity $[49,50]$. In our study, IL-6 and TNF$\alpha$ mRNA are upregulated in the epididymal adipose tissue of IR offspring. It has been recently shown that adipose tissue, during insulin-resistant state, secrete IL- 6 and TNF$\alpha$ [14]. Moreover, high levels of TNF- $\alpha$ and IL-6 may also downregulate the expression of adiponectin [51].

In IR offspring, increased IL-6 might not only diminish insulin sensitivity by suppressing insulin signal transduction but also interfere with anti-inflammatory effect of insulin, and might favour inflammation during insulin-resistance state, as demonstrated by Dandona et al. [24]. Furthermore, 
IL-6 has been shown to be one of the mediators of hyperinsulinemic state [52]. It is interesting to mention that $10 \%-35 \%$ of the body's basal circulating IL- 6 is derived from adipose tissue and a positive correlation has been found between insulin resistance and circulating IL-6 [24]. Thus, we can state that hyperglycemia may be one of the factors implicated in IL-6 expression [24].

As far as inflammation in adipose tissue is concerned, we observed that CD14 and CD68 mRNA expression, but not F4/80, was upregulated in epididymal adipose tissue of IR offspring. These observations suggested that the adipocytes seemed to be differentiated into macrophagelike cells, as they expressed upregulated transcripts of CD14 and CD68 antigens, generally expressed by macrophages. However, there was no peripheral macrophages infiltration into epididymal adipose tissue, as the expression of F4/80, a true macrophage marker, was downregulated. Our results are in close agreement with those of Khazen et al. [53] who have reported that murine and human adipose tissue express CD14 and CD68, but not F4/80, both at protein and mRNA levels. Besides, Cousin et al. [54] have demonstrated that preadipocytes can be differentiated into macrophage-like cells which are stained with MOMA-2, a marker of monocyte-macrophage lineage, but are negative for F4/80. Besides, the lack of expression of MCP-1, a monocytes/macrophages chemoattractant, provides an additional argument for the absence of macrophages in epididymal adipose tissue of these animals. Moreover, it has been reported that RANTES and its receptor CCR5 are expressed principally on infiltrated $\mathrm{T}$ cells in adipose tissue during insulin resistance in high-fat diet-fed animals [14]. In our study, we could not detect both RANTES and CCR5 mRNA in epididymal adipose tissue of the IR mice. Furthermore, we did not observe the expression of TCR-alpha mRNA, suggesting that $\mathrm{T}$ cells are not infiltrated in epididymal adipose tissue of these mice. These findings corroborate the study of $\mathrm{Xu}$ et al. [22] who did not observe infiltration of $\mathrm{T}$ cells in white adipose tissue of both genetic and high-fat dietinduced mouse models of insulin resistance.

In vitro differentiated adipocytes have been shown to express TLR-2 [55] and the polymorphism of TLR-2 gene significantly correlates with a higher risk of insulin resistance [56]. We observed that TLR-2 mRNA expression increased in epididymal adipose tissue of IR mice and these observations corroborate the report of Murakami et al. [36] who have shown that the adipocytes, in rats fed a high-fat diet, coexpress TNF- $\alpha$ and TLR-2, and these adipocytes do not express F4/80. Besides, these authors [36] have suggested that adipocytes coexpressing TNF- $\alpha$ and TLR-2 might be "pathological" cells in fat tissue, promoting the development of insulin resistance as seen in metabolic syndrome. Finally, we observed that IR offspring exhibited a high level of FFA in serum and liver. Murakami et al. [36] have also shown that increased FFA level may activate inflammatory pathway in adipocytes, and TLR-2 seems to contribute to this pathway by inducing TNF- $\alpha$ production.

Therefore, the novelty of our study is that, in this model of insulin resistance without obesity, the inflammatory state of epididymal adipose tissue of IR offspring is intrinsic to this organ which cells seemed to be differentiated into macrophage-like cells, but not because of the macrophages or $\mathrm{T}$ cell infiltration.

\section{Conclusion}

To sum up, our study demonstrates that the hyperinsulinemia, observed in IR offspring of diabetic dams, appears as a pathological model of insulin resistance which is associated with altered expression of genes of insulin transcription factors and glucose metabolism-related enzymes. Our study will help understand the mechanisms of insulin resistance in offspring, born to diabetic mothers, as several studies have shown that these offspring are prone to develop metabolic syndrome $[5,44]$.

\section{Conflict of Interests}

All of the authors have nothing to declare as far as the conflict of interests is concerned.

\section{Abbreviations}

$\begin{array}{ll}\text { IR: } & \text { Insulin-resistant } \\ \text { GK: } & \text { Glucokinase } \\ \text { Pdx-1: } & \text { Pancreatic and duodenal homeobox-1 } \\ \text { Nkx6.1: } & \text { NK6 transcription factor related-locus-1 } \\ \text { MCP-1: } & \text { Monocyte-chemoattractant protein-1 } \\ \text { RANTES: } & \text { Regulated on activation of normal T cell } \\ & \text { expressed and secreted } \\ \text { ChREBP: } & \text { Carbohydrate response element-binding } \\ & \text { protein } \\ \text { SREBP1c: } & \text { Sterol response element-binding protein 1c } \\ \text { FAT/CD36: } & \text { Fatty acid translocase } \\ \text { TG: } & \text { Triglyceride } \\ \text { TLR: } & \text { Toll-like receptor } \\ \text { FFA: } & \text { Free fatty acids. }\end{array}$

\section{Acknowledgments}

The authors thank the French Foreign Office and the French Ministry of Higher Education and Research which sanctioned the contingent grants for this work. A. Yessoufou received a scholarship from the Islamic Development Bank.

\section{References}

[1] P.-J. Guillausseau and M. Laloi-Michelin, "Pathogenesis of type 2 diabetes mellitus," Revue de Medecine Interne, vol. 24, no. 11, pp. 730-737, 2003.

[2] M. J. Pagliassotti, S. M. Knobel, K. A. Shahrokhi, A. M. Manzo, and J. O. Hill, "Time course of adaptation to a high-fat diet in obesity-resistant and obesity-prone rats," American Journal of Physiology, vol. 267, no. 3, pp. R659-R664, 1994.

[3] R. Buettner, J. Schölmerich, and L. C. Bollheimer, "High-fat diets: modeling the metabolic disorders of human obesity in rodents," Obesity, vol. 15, no. 4, pp. 798-808, 2007.

[4] A. Yessoufou, N. Soulaimann, S. A. Merzouk et al., "N-3 fatty acids modulate antioxidant status in diabetic rats and their 
macrosomic offspring," International Journal of Obesity, vol. 30, no. 5, pp. 739-750, 2006.

[5] H. Merzouk, S. Madani, A. Hichami, J. Prost, J. Belleville, and N. A. Khan, "Age-related changes in fatty acids in obese offspring of streptozotocin-induced diabetic rats," Obesity Research, vol. 10, no. 7, pp. 703-714, 2002.

[6] A. Yessoufou, A. Hichami, P. Besnard, K. Moutairou, and N. A. Khan, "Peroxisome proliferator-activated receptor $\alpha$ deficiency increases the risk of maternal abortion and neonatal mortality in murine pregnancy with or without diabetes mellitus: modulation of T cell differentiation," Endocrinology, vol. 147, no. 9, pp. 4410-4418, 2006.

[7] J. D. Johnson, N. T. Ahmed, D. S. Luciani et al., "Increased islet apoptosis in Pdx1+/- mice," Journal of Clinical Investigation, vol. 111, no. 8, pp. 1147-1160, 2003.

[8] N. Sander, L. Sussel, J. Conners et al., "Homeobox gene Nkx6.1 lies downstream of $\mathrm{Nkx} 2.2$ in the major pathway of $\beta$-cell formation in the pancreas," Development, vol. 127 , no. 24 , pp. 5533-5540, 2000.

[9] J. C. Schisler, P. B. Jensen, D. G. Taylor et al., "The Nkx6.1 homeodomain transcription factor suppresses glucagon expression and regulates glucose-stimulated insulin secretion in islet beta cells," Proceedings of the National Academy of Sciences of the United States of America, vol. 102, no. 20, pp. 7297-7302, 2005.

[10] H. M. Docherty, C. W. Hay, L. A. Ferguson, J. Barrow, E. Durward, and K. Docherty, "Relative contribution of PDX1, MafA and E47/ $\beta 2$ to the regulation of the human insulin promoter," Biochemical Journal, vol. 389, no. 3, pp. 813-820, 2005.

[11] H. Waki and P. Tontonoz, "Endocrine functions of adipose tissue," Annual Review of Pathology, vol. 2, pp. 31-56, 2007.

[12] S. P. Weisberg, D. McCann, M. Desai, M. Rosenbaum, R. L. Leibel, and A. W. Ferrante Jr., "Obesity is associated with macrophage accumulation in adipose tissue," Journal of Clinical Investigation, vol. 112, no. 12, pp. 1796-1808, 2003.

[13] M. Triantafilou and K. Triantafilou, "Lipopolysaccharide recognition: CD14, TLRs and the LPS-activation cluster," Trends in Immunology, vol. 23, no. 6, pp. 301-304, 2002.

[14] H. Wu, S. Ghosh, X. D. Perrard et al., "T-cell accumulation and regulated on activation, normal $\mathrm{T}$ cell expressed and secreted upregulation in adipose tissue in obesity," Circulation, vol. 115, no. 8, pp. 1029-1038, 2007.

[15] D. Maksimovic-Ivanic, V. Trajkovic, D. J. Miljkovic, M. Mostarica Stojkovic, and S. Stosic-Grujicic, "Down-regulation of multiple low dose streptozotocin-induced diabetes by mycophenolate mofetil," Clinical and Experimental Immunology, vol. 129, no. 2, pp. 214-223, 2002.

[16] R. R. Buggage, D. M. Matteson, D. F. Shen, B. Sun, N. Tuaillon, and C.-C. Chan, "Effect of sex hormones on experimental autoimmune uveoretinitis (EAU)," Immunological Investigations, vol. 32, no. 4, pp. 259-273, 2003.

[17] P. Costet, C. Legendre, J. Moré, A. Edgar, P. Galtier, and T. Pineau, "Peroxisome proliferator-activated receptor $\alpha$ isoform deficiency leads to progressive dyslipidemia with sexually dimorphic obesity and steatosis," Journal of Biological Chemistry, vol. 273, no. 45, pp. 29577-29585, 1998.

[18] E. G. Bligh and W. J. Dyer, "A rapid method of total lipid extraction and purification," Canadian Journal of Biochemistry and Physiology, vol. 37, no. 8, pp. 911-917, 1959.

[19] H. T. Slover and E. Lanza, "Quantitative analysis of food fatty acids by capillary gas chromatography," Journal of the American Oil Chemists' Society, vol. 56, no. 12, pp. 933-943, 1979.
[20] B. Wicksteed, C. Alarcon, I. Briaud, M. K. Lingohr, and C. J. Rhodes, "Glucose-induced translational control of proinsulin biosynthesis is proportional to preproinsulin mRNA levels in islet beta-cells but not regulated via a positive feedback of secreted insulin," Journal of Biological Chemistry, vol. 278, no. 43, pp. 42080-42090, 2003.

[21] S.-S. Im, S.-Y. Kim, H.-I. Kim, and Y.-H. Ahn, "Transcriptional regulation of glucose sensors in pancreatic $\beta$ cells and liver," Current Diabetes Reviews, vol. 2, no. 1, pp. 11-18, 2006.

[22] H. Xu, G. T. Barnes, Q. Yang et al., "Chronic inflammation in fat plays a crucial role in the development of obesity-related insulin resistance," Journal of Clinical Investigation, vol. 112, no. 12, pp. 1821-1830, 2003.

[23] S. S.-T. Lee, T. Pineau, J. Drago et al., "Targeted disruption of the $\alpha$ isoform of the peroxisome proliferator-activated receptor gene in mice results in abolishment of the pleiotropic effects of peroxisome proliferators," Molecular and Cellular Biology, vol. 15, no. 6, pp. 3012-3022, 1995.

[24] P. Dandona, A. Aljada, and A. Bandyopadhyay, "Inflammation: the link between insulin resistance, obesity and diabetes," Trends in Immunology, vol. 25, no. 1, pp. 4-7, 2004.

[25] N. D. Oakes, G. J. Cooney, S. Camilleri, D. J. Chisholm, and E. W. Kraegen, "Mechanisms of liver and muscle insulin resistance induced by chronic high-fat feeding," Diabetes, vol. 46, no. 11, pp. 1768-1774, 1997.

[26] B. Ahrén, T. Gudbjartsson, A. N. Al-Amin et al., "Islet perturbations in rats fed a high-fat diet," Pancreas, vol. 18, no. 1, pp. 75-83, 1999.

[27] M. K. Lingohr, R. Buettner, and C. J. Rhodes, "Pancreatic $\beta$-cell growth and survival-a role in obesity-linked type 2 diabetes?" Trends in Molecular Medicine, vol. 8, no. 8, pp. 375384, 2002.

[28] M. Vercheval, R. De Hertogh, S. Pampfer et al., "Experimental diabetes impairs rat embryo development during the preimplantation period," Diabetologia, vol. 33, no. 4, pp. 187-191, 1990.

[29] I. López-Soldado and E. Herrera, "Different diabetogenic response to moderate doses of streptozotocin in pregnant rats, and its long-term consequences in the offspring," Experimental Diabesity Research, vol. 4, no. 2, pp. 107-118, 2003.

[30] K. C. Herold, V. Vezys, Q. Sun et al., "Regulation of cytokine production during development of autoimmune diabetes induced with multiple low doses of streptozotocin," Journal of Immunology, vol. 156, no. 9, pp. 3521-3527, 1996.

[31] A. A. Rossini, R. M. Williams, M. C. Appel, and A. A. Like, "Complete protection from low-dose streptozotocin-induced diabetes in mice," Nature, vol. 276, no. 5684, pp. 182-184, 1978.

[32] M. E. Elder and N. K. Maclaren, "Identification of profound peripheral $\mathrm{T}$ lymphocyte immunodeficiencies in the spontaneously diabetic BB rat," Journal of Immunology, vol. 130, no. 4, pp. 1723-1731, 1983.

[33] D. V. Serreze, K. Hamaguchi, and E. H. Leiter, "Immunostimulation circumvents diabetes in NOD Lt mice," Journal of Autoimmunity, vol. 2, no. 6, pp. 759-776, 1989.

[34] A. Müller, P. Schott-Ohly, C. Dohle, and H. Gleichmann, "Differential regulation of Th1-type and Th2-type cytokine profiles in pancreatic islets of C57BL/6 and BALB/c mice by multiple low doses of streptozotocin," Immunobiology, vol. 205, no. 1, pp. 35-50, 2002.

[35] G. Bienvenu, D. Seurin, Y. Le Bouc, P. Even, S. Babajko, and C. Magnan, "Dysregulation of energy homeostasis in mice overexpressing insulin-like growth factor-binding protein 6 in the brain," Diabetologia, vol. 48, no. 6, pp. 1189-1197, 2005. 
[36] K. Murakami, H. Bujo, H. Unoki, and Y. Saito, "High fat intake induces a population of adipocytes to co-express TLR2 and TNF $\alpha$ in mice with insulin resistance," Biochemical and Biophysical Research Communications, vol. 354, no. 3, pp. 727734, 2007.

[37] B. Leibiger, T. Moede, S. Uhles, P. O. Berggren, and I. B. Leibiger, "Short-term regulation of insulin gene transcription," Biochemical Society Transactions, vol. 30, no. 2, pp. 312 $317,2002$.

[38] M. C. Lawrence, K. McGlynn, B.-H. Park, and M. H. Cobb, "ERK1/2-dependent activation of transcription factors required for acute and chronic effects of glucose on the insulin gene promoter," Journal of Biological Chemistry, vol. 280, no. 29, pp. 26751-26759, 2005.

[39] U. Ahlgren, J. Jonsson, L. Jonsson, K. Simu, and H. Edlund, “ $\beta$ cell-specific inactivation of the mouse Ipf1/Pdx1 gene results in loss of the $\beta$-cell phenotype and maturity onset diabetes," Genes and Development, vol. 12, no. 12, pp. 1763-1768, 1998.

[40] R. Dentin, J.-P. Pégorier, F. Benhamed et al., "Hepatic glucokinase is required for the synergistic action of ChREBP and SREBP-1c on glycolytic and lipogenic gene expression," Journal of Biological Chemistry, vol. 279, no. 19, pp. 20314 20326, 2004.

[41] H. Zitzer, W. Wente, M. B. Brenner et al., "Sterol regulatory element-binding protein 1 mediates liver $\mathrm{X}$ receptor- $\beta$ induced increases in insulin secretion and insulin messenger ribonucleic acid levels," Endocrinology, vol. 147, no. 8, pp. 3898-3905, 2006.

[42] R. H. Knopp, M. R. Warth, D. Charles et al., "Lipoprotein metabolism in pregnancy, fat transport to the fetus, and the effects of diabetes," Biology of the Neonate, vol. 50, no. 6, pp. 297-317, 1986.

[43] E. Shafrir and S. Khassis, "Maternal-fetal fat transport versus new fat synthesis in the pregnant diabetic rat," Diabetologia, vol. 22, no. 2, pp. 111-117, 1982.

[44] H. Merzouk, S. Madani, D. C. Sari, J. Prost, M. Bouchenak, and J. Belleville, "Time course of changes in serum glucose, insulin, lipids and tissue lipase activities in macrosomic offspring of rats with streptozotocin-induced diabetes," Clinical Science, vol. 98, no. 1, pp. 21-30, 2000.

[45] L. Rahib, N. K. MacLennan, S. Horvath, J. C. Liao, and K. M. Dipple, "Glycerol kinase deficiency alters expression of genes involved in lipid metabolism, carbohydrate metabolism, and insulin signaling," European Journal of Human Genetics, vol. 15, no. 6, pp. 646-657, 2007.

[46] P. Trayhurn and I. S. Wood, "Adipokines: inflammation and the pleiotropic role of white adipose tissue," British Journal of Nutrition, vol. 92, no. 3, pp. 347-355, 2004.

[47] J.-M. Atègbo, O. Grissa, A. Yessoufou et al., "Modulation of adipokines and cytokines in gestational diabetes and macrosomia," Journal of Clinical Endocrinology and Metabolism, vol. 91, no. 10, pp. 4137-4143, 2006.

[48] M. Guerre-Millo, C. Rouault, P. Poulain et al., "PPAR- $\alpha$ null mice are protected from high-fat diet-induced insulin resistance," Diabetes, vol. 50, no. 12, pp. 2809-2814, 2001.

[49] Y. Arita, S. Kihara, N. Ouchi et al., "Paradoxical decrease of an adipose-specific protein, adiponectin, in obesity," Biochemical and Biophysical Research Communications, vol. 257, no. 1, pp. 79-83, 1999.

[50] N. Stefan, B. Vozarova, T. Funahashi et al., "Plasma adiponectin concentration is associated with skeletal muscle insulin receptor tyrosine phosphorylation, and low plasma concentration precedes a decrease in whole-body insulin sensitivity in humans," Diabetes, vol. 51, no. 6, pp. 1884-1888, 2002.

[51] A. S. Lihn, B. Richelsen, S. B. Pedersen et al., "Increased expression of TNF- $\alpha$, IL-6, and IL-8 in HALS: implications for reduced adiponectin expression and plasma levels," American Journal of Physiology, vol. 285, no. 5, pp. E1072-E1080, 2003.

[52] A. Cartier, I. Lemieux, N. Alméras, A. Tremblay, J. Bergeron, and J.-P. Després, "Visceral obesity and plasma glucoseinsulin homeostasis: contributions of interleukin-6 and tumor necrosis factor- $\alpha$ in men," Journal of Clinical Endocrinology and Metabolism, vol. 93, no. 5, pp. 1931-1938, 2008.

[53] W. Khazen, J.-P. M'Bika, C. Tomkiewicz et al., "Expression of macrophage-selective markers in human and rodent adipocytes," FEBS Letters, vol. 579, no. 25, pp. 5631-5634, 2005.

[54] B. Cousin, O. Munoz, M. Andre et al., "A role for preadipocytes as macrophage-like cells," FASEB Journal, vol. 13, no. 2, pp. 305-312, 1999.

[55] S. J. Creely, P. G. McTernan, C. M. Kusminski et al., "Lipopolysaccharide activates an innate immune system response in human adipose tissue in obesity and type 2 diabetes," American Journal of Physiology, vol. 292, no. 3, pp. E740-E747, 2007.

[56] J.-J. Yim, L. Ding, A. A. Schäffer, G. Y. Park, Y.-S. Shim, and S. M. Holland, "A microsatellite polymorphism in intron 2 of human Toll-like receptor 2 gene: functional implications and racial differences," FEMS Immunology and Medical Microbiology, vol. 40, no. 2, pp. 163-169, 2004. 


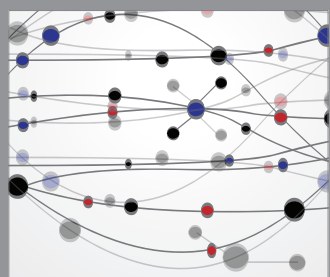

The Scientific World Journal
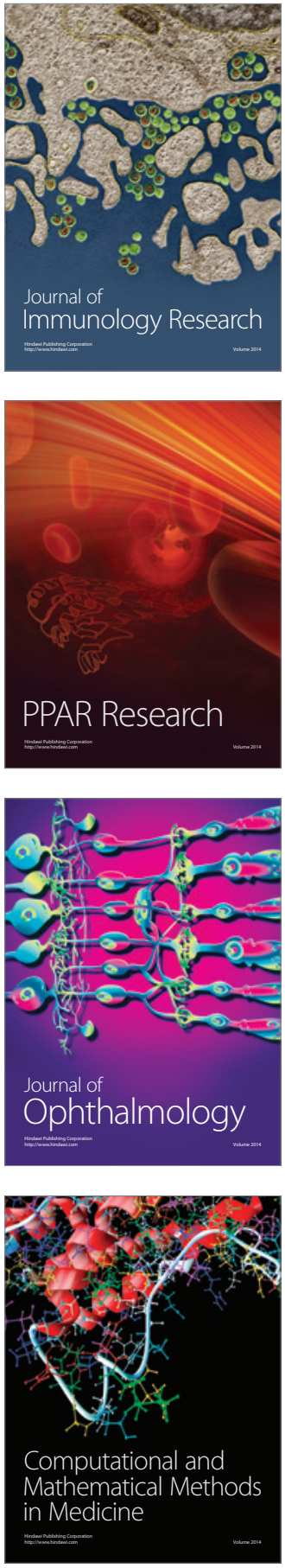

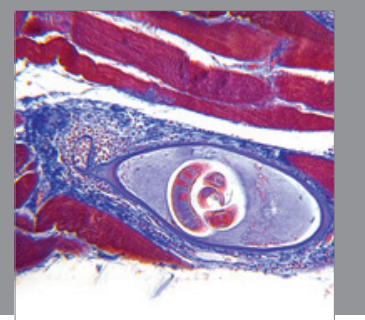

Gastroenterology

Research and Practice
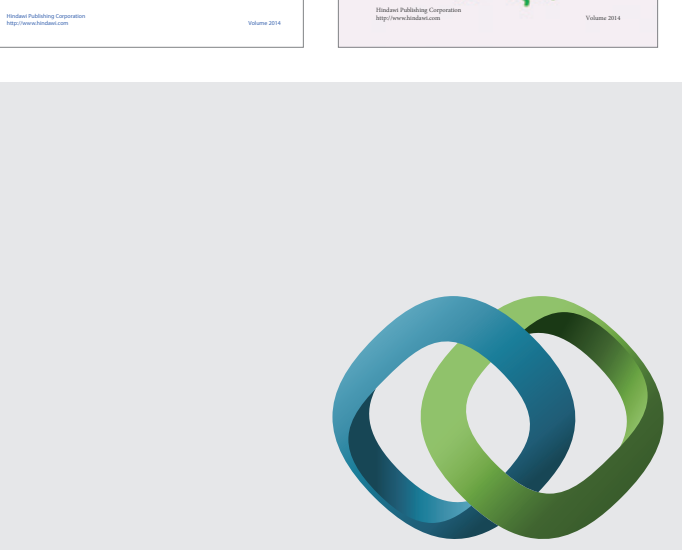

\section{Hindawi}

Submit your manuscripts at

http://www.hindawi.com
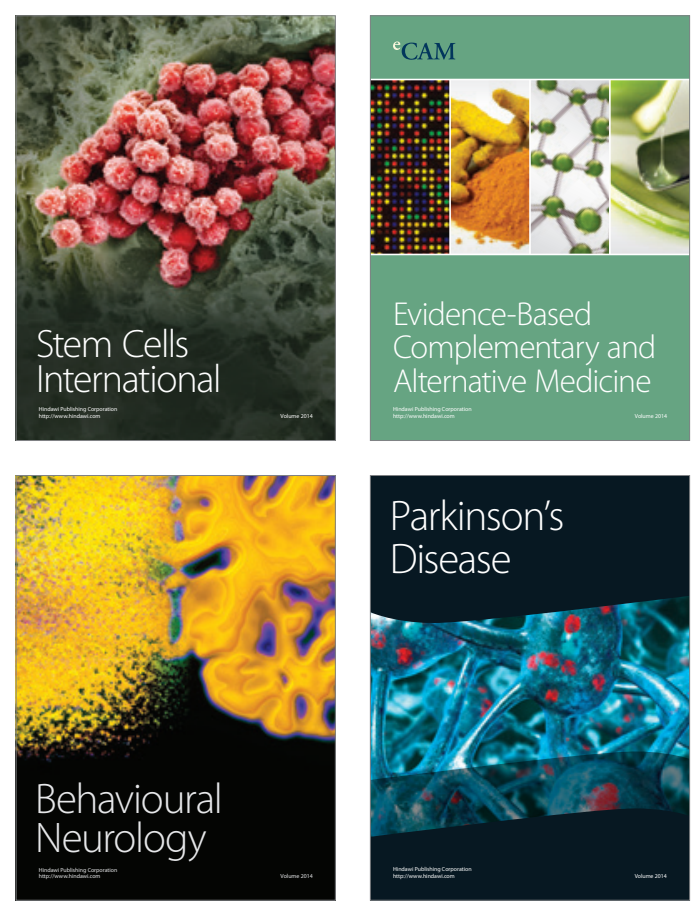

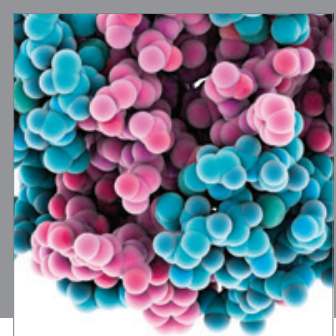

Journal of
Diabetes Research

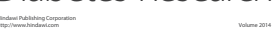

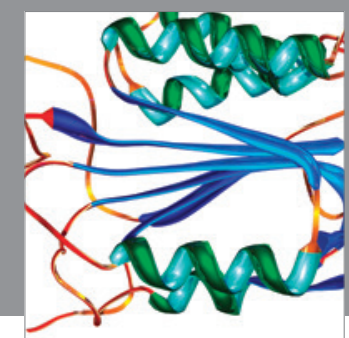

Disease Markers
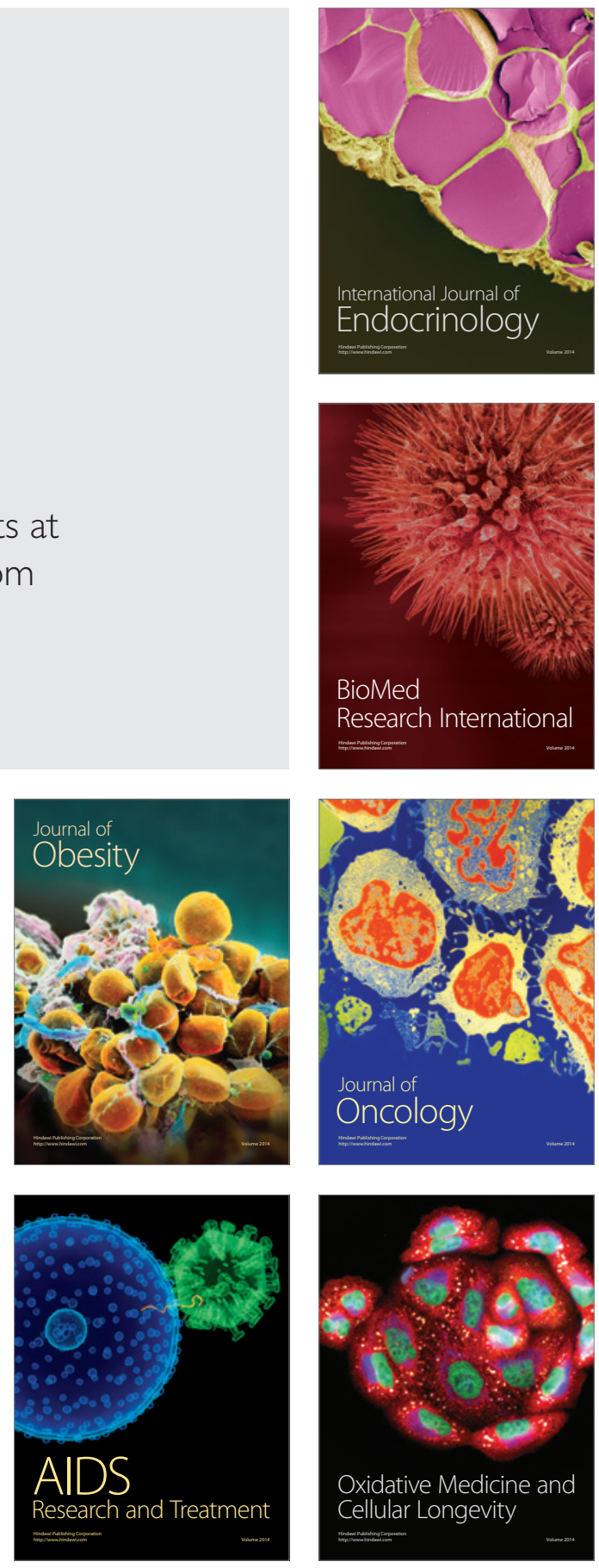